\title{
Analysis of the Present Situation of the Cultivation of Scientific Research and Innovation Ability of Medical Students and Exploration of the Scientific Research Training Mode
}

\author{
Yan Pan ( $\nabla$ py19841205@163.com ) \\ The First Affiliated Hospital Of BengBu Medical College \\ Lei Liu \\ The First Affiliated Hospital of BengBu Medical College \\ Bao-chao Chang \\ The First Affiliated Hospital Of BengBu Medical College

\section{Zheng Chen} \\ TheFirst Affiliated Hospital Of BengBu Medical College \\ Wei-dong Chen \\ TheFirst Affiliated Hospital Of Medical College \\ Hui-juan Yang \\ Bengbu Medical College \\ Zhi-jie Mei \\ Bengbu Medical College
}

Research article

Keywords: College students' entrepreneurship training program; Scientific research and teaching mode; Time arrangement; Scientific research atmosphere; Laboratory opening

Posted Date: April 1st, 2020

DOI: https://doi.org/10.21203/rs.3.rs-18327/v1

License: (c) (1) This work is licensed under a Creative Commons Attribution 4.0 International License. Read Full License 


\section{Abstract}

Background To investigate the problems and countermeasures faced by five-year clinical medical students in an entrepreneurship training programme for medical students from different perspectives to promote medical teaching reforms.

Methods A total of 600 five-year clinical medicine majors (grades 16-18) of Bengbu Medical College (including those who did and did not participate in large-scale innovative projects) were studied by means of network questionnaires and interviews. Statistical analysis was used to analyse the results.

Results Students generally hope to improve the teaching quality and teaching mode of scientific research; they have strong interest in scientific research and hope to conduct scientific research training in their spare time without affecting their studies. Moreover, students hope to improve the incentive policy for innovation and to optimize the funding for scientific research and the policy of laboratory opening.

Conclusions Clinical medical students in our hospital attach great importance to the cultivation of scientific research ability, understand the problems faced by medical undergraduates in the process of innovative projects, and provide specific quantitative data for the reform of medical education modes to cultivate the innovative ability of medical students.

\section{Background}

Innovation is the soul of a nation's progress. It is the responsibility of scientific research innovation in colleges and universities to improve students' quality and cultivate innovative talent through scientific research activities. How to train innovative talent at the undergraduate level of higher medical education has long been a concern of medical educators, but the scientific research value of higher medical education in China has not received due attention. The scientific research level of undergraduates is not high, and their scientific research consciousness is not strong. In 2010, the Medical Department launched an innovative experimental project for medical undergraduates that aims to "promote the cultivation of students' innovative spirit, team consciousness and practical ability, and improve students' ability to comprehensively use knowledge and research ability". The goal is to improve the scientific research ability of medical students. On this basis, our school has conducted a number of "great innovation" projects to guide the training of medical innovative talent [1], but room for improvement remains [3]. Taking students as the main body, this paper investigates the problems related to the development of innovative topics and desired countermeasures to provide data for training medical students and developing a new medical education model.

\section{Methods}

1. A total of 600 students majoring in five-year clinical medicine (Grades 16-18) at Bengbu Medical College were divided into two groups: the large-scale innovation group and the non-large-scale innovation group. 
2. Research methods: Online questionnaires and interviews were used. The design and release of the network questionnaire and data collection are completed online, and each WeChat account is filled in anonymously once. The questionnaire focuses on the scientific research teaching mode, time arrangement, scientific research atmosphere, reward mechanism and experimental conditions from multiple perspectives. The goals of the interviews and research with the students, project instructors and managers in charge of the projects are to understand their views and provide suggestions for undergraduate participation in projects.

3. Statistical analysis of the results of the questionnaire was performed in Excel. The count data were expressed as the number of cases and percentage, and the comparison between groups was analysed by $\chi 2$ test $(P<0.05)$. All statistical analyses were performed with SPSS 23.0 statistical software. The interview data were analysed by descriptive statistical analysis.

\section{Results}

A total of 600 questionnaires were distributed, and 568 valid questionnaires were recovered, for a recovery rate of $94.7 \%$. Among the respondents, clinical medical students of grades 16,17 and 18 accounted for $234(41.2 \%), 154(27.11 \%)$, and 180 (31.69\%), and there were 256 males (43.66\%) and 194 students $(34.15 \%)$ who had participated in or were participating in large-scale entrepreneurship programmes.

1. The scientific research and teaching mode desired by students

1.1 The survey results show that more than $70 \%$ of the students in both groups $(84.54 \%$ in the large-scale innovation group and $75.4 \%$ in the non-large-scale innovation group) think that essential courses on scientific research design, experimental records and thesis writing are needed. Furthermore, the scientific research courses should focus on experimental technology, research topic selection and design, literature retrieval and reading, data analysis, and paper writing. The results are shown in Table 1.

1.2 In terms of teaching methods, $47.89 \%(46.39 \%)$ of students prefer practical projects, while $34.51 \%$ $(41.24 \%)$ of students want teacher-student interaction.

Among the students, $66.31 \%$ wanted their mentors to participate in the project in person, and $20.42 \%$ (19.59\% 20.86\%) wanted their teachers to guide them macroscopically. In terms of instructor arrangement, nearly half of the students $(49.3 \%, 44.33 \%$ and $51.87 \%)$ would like a "double tutor system", such as joint guidance of college and clinical teachers, and many preferred "assistance from members of the research group"; see Table 2 for details.

2. Timing

2.1 The results of the survey on the timing of the implementation of a project show that $82.75 \%$ of the students $(92.78 \%$ of Dacheng, $77.54 \%$ of non-Dacheng) believe that conducting scientific research projects has a positive effect and can improve their comprehensive abilities. Only $5.28 \%$ ( $0 \%$ of the 
Dacheng students $8.02 \%$ of the non- Dacheng students) think that scientific research projects will consume considerable amounts of time and affect their normal study schedule and life. A significant difference was observed between the two groups $(P<0.01)$. In terms of the time spent each week in the implementation of a project, $64.08 \%$ of the students thought that $10 \mathrm{Mel} 20 \mathrm{~h}$ was the most appropriate and would not have a substantial impact on their studying and life. In terms of time allocation, students were willing to spend their time on literature review (28.17\% of students) and experiment execution (35.21\% of students), and there was a significant difference between the two groups $(P<0.05)$. See Table 3 for details.

\subsection{Attitude towards sacrificing holidays to complete scientific research and training}

The survey results show that $71.13 \%$ of the students in the large-scale entrepreneurship group $(54.01 \%$ in the non-large-scale entrepreneurship group) are willing to use holidays to complete scientific research training, and $25.77 \%$ (37.43\% in the non-large-scale entrepreneurship group) are willing to receive targeted training in the process of implementation: only $1.03 \%$ of the students rejected such training. A significant difference was observed between the two groups $(P<0.05)$. A total of $14.43 \%$ of the students in the major innovation group (17.65\% in the non-major entrepreneurship group) were willing to sacrifice all their holidays, and $63.92 \%(56.15 \%)$ of the students were willing to sacrifice most of their holidays. The specific results are shown in Table 4 and figure 1.

\section{The creation of a scientific research atmosphere}

3.1 The results of the survey show that $81.44 \%$ of the students in the Dachang group think that casebased teaching combined with problem-based learning (PBL) can enhance their interest in scientific research and that the joint teaching method is the most effective. By contrast, $81.82 \%$ of the students in the non-Dai Chuang group hold the same view. See Table 5 for details.

3.2 The effect of classroom discussion teaching on the cultivation of interest in scientific research

A total of $81.44 \%$ of the students in the major innovation group ( $82.89 \%$ in the non-major innovation group) thought that discussion could stimulate students' enthusiasm to conduct scientific research, while $77.32 \%$ (70.59\% in the non-major innovation group) thought that discussion could lead to improved thinking. More than $25 \%$ of the students in the two groups believed that discussion could stimulate students' interest and arouse their enthusiasm for learning.

\section{Reward mechanism}

4.1 Measures to promote the development of large-scale innovative projects

The innovation group preferred to increase the laboratory opening, and $35.29 \%$ of the students in the nonlarge-scale innovation group preferred to optimize the application process and conduct scientific research lectures for undergraduates. See figure 2 for details. 
4.2 Regarding "whether you want to add to the scholarship programme or not", $91.75 \%$ of the students in the innovation group did, and $75.4 \%$ of the students in the non-large innovation group held the same view, but $24.60 \%$ of the students disagreed. There was a significant difference between the two groups $(P<$ 0.01 ); see Table 6.

4.3 For the multiple choice about "what rewards should students who participate in Dacheng" receive, $81.44 \%$ of the students in the Dachang group ( $67.91 \%$ of non-Dai Chuang) thought that participation in the Dai Chuang project should be used as a bonus programme for scholarship and research, and $64.95 \%$ (54.55\% of the non-Dachang Group) thought that participation should support the publication of papers. More than 25\% of the students in the two groups preferred the former; see figures 3 and 4 .

5. Broaden the experimental platform and integrate experimental resources

5.1 The two groups of students agree that opening laboratories to students can strengthen the sense of teamwork and promote the cultivation of high-quality talent.See figure 5 for details.

A Very good. The purpose of open laboratories is to improve the quality of teaching and achieve the goal of cultivating high-quality talent.

B The experiment is based on a team-based division of labor and cooperation to cultivate students' sense of teamwork.

C Scientific research is closely related to the development of experiments, and students' rigorous scientific attitude and comprehensive quality have been improved through the process of continuous speculation, verification and comprehension.

D Experience the various experimental operations in the laboratory so that the level of teaching and scientific research can be improved through integration.

E An open laboratory enriches and improves the structure and flexibility of experimental teaching, enabling students to innovate.

5.2 We also gained a preliminary understanding of the two groups of students' thoughts on the opening hours of the laboratory. In view of the heavy task load and time shortage of medical students, most students want the laboratory to be open all day and hope that teachers or graduate students will be on duty for effective supervision and management. See figures 6 and 7.

A Open all day means that the laboratory is open to students all day if conditions permit

B Regular opening refers to the laboratory's opening at a fixed time based on actual conditions.

C Regular opening refers to the laboratory's opening at a fixed time based on actual conditions. 
D Staged opening refers to the practice of laboratory opening at certain stages to support the completion of students' learning tasks.

E Other

6. Allocation of scientific research funds

When asked "how the school can improve the allocation of funds", $79.28 \%$ of the students in the Dai Chuang group (65.78\% of the non-Dachang Group) wanted to adjust the proportion of funds invested in national and school-level projects, whereas $10.31 \%$ (non-Dachang $19.25 \%$ ) thought that the number of projects should be reduced and their quality should be improved. A total of $2.06 \%$ (non-Dachang $8.02 \%$ ) of the students wanted to change the method of reporting accounts and strengthen the review process. Moreover, a total of $3.09 \%$ (non-major venture $3.21 \%$ ) of the students wanted funding between the research groups to complement each other, whereas 5.15\% (non-major venture $3.74 \%$ ) of students did not think such funding was required. See figure 8 for details.

\section{Discussion}

At present, despite the development and specific implementation of the large-scale innovation project, we find that higher medical education in China is still restricted by the traditional education system, and increasingly more students are aware of the shortcomings of the existing scientific research and training model. Therefore, we must improve the existing methods of scientific research and teaching.

1. Improvement of Scientific Research and Teaching Mode Medical students currently have an unprecedented variety of ways to acquire scientific research knowledge and have a strong awareness of autonomous learning. Compared with the traditional teaching model, students involved in research want to conduct targeted and systematic scientific research and training courses before carrying out largescale innovative projects. Some studies have found that the addition of experimental operation courses can improve students' innovative thinking ability [4], which coincides with the psychological needs of our students. However, the lack of scientific research experience limits students' exploration of scientific research to a certain extent.

More than $80 \%$ of students hope to continuously cultivate scientific research methods and thinking in practice under the guidance of teachers, which requires us to attach importance to practical teaching and to actively build a practical teaching system that is suitable for the cultivation of innovative talent in order to cultivate students' innovative spirit and practical ability. The teacher's guidance method is important in the process of cultivating students' innovative ability. When asked about "the teaching method of scientific research courses you want" and the desired "guidance mode" and "instructor arrangement", most of the students preferred teaching via practical projects and hoped that the teacher would participate in the project. During the interviews, the students also reported that communication with the instructor was not sufficiently frequent and that a lack of guidance at important stages hinders the establishment of scientific research thinking, causing students to become "simple experimenters". This 
result is contrary to the purpose of our innovation project. We urgently need to improve the communication frequency between teachers and students so that students can obtain detailed, comprehensive and in-depth guidance from mentors in the development of the project to cultivate scientific research ability.

Moreover, in terms of instructor arrangement, students very much hope to have a "double tutoring system" or "research group staff to help", especially students in hospital internships (usually during the summer vacation of sophomore year). These students find that it is very difficult for clinical teachers to give attention to both scientific research and clinical work, and the students hope that college teachers and clinical teachers can guide them together. Alternatively, full consideration should be given to the role of graduate students on the scientific research team. The "double mentor system" can strengthen communication between students and mentors, and "group help" can encourage group discussions and overcome limitations in thinking. The staffing arrangements of the two groups are gradually gaining wider recognition [5].

2. Rationalization of scheduling The survey results show that most of the students affirm the positive role of "great innovation" in their willingness to apply for large-scale innovation projects, but many non-largescale innovation students believe that large-scale innovation will only increase their academic burden. This perceived increased burden may be one of the reasons many students decline to apply for innovative projects. Medical courses and rotation arrangements are compact, and the actual time for scientific research is less abundant. Spare time is used to review courses and participate in scientific research training, and there is a certain degree of difficulty in this process. Therefore, the reasonable arrangement of time spent on professional knowledge learning and scientific research training has become a primary problem to be solved. By means of the establishment of a long-term mechanism of scientific research practice, we can encourage and guide students who have spare time and interest to remain in the laboratory after school to engage in formal scientific research work, improve the summer scientific research programme, make experimental plans in advance, arrange experimental personnel, and strive for students to actively participate in early rotational training without neglecting the study of basic knowledge [6]. In an investigation of summer scientific research rotational training of medical students at Shanghai Jiaotong University, Luo Deng et al found that such training not only does not affect students' daily study but can also strengthen students' scientific research consciousness and skills in a short period of time. This training lays a foundation for students' comprehensive scientific research quality and innovation ability and improves medical students' scientific research thinking and thesis writing [7]. When asked about their "views of summer training rotation", more than $90 \%$ of the students in the two groups thought were very willing to participate in summer scientific research training without affecting their lives and were willing to spend most of their time on such training. This result indicates that students strongly support summer scientific research training.

3. The creation of scientific research atmosphere PBL, developed by the American scholar Barrows in 1969, emphasizes problem-centred, student-centred, autonomous and cooperative learning and effectively integrates curriculum learning and scientific research training [8]. However, case-based 
teaching combined with PBL teaching has not been applied to early scientific research training in China. Einstein once said: "interest is the best teacher, interest is always more important than responsibility". Focus on the cultivation of the academic atmosphere can start from the cultivation of interest. The questionnaire and interview data indicated that the two groups of students believe that the combination of the two models should be integrated into scientific research training and project development. On the one hand, students' interest in scientific research can be cultivated via a large number of examples in the classroom [9]. On the other hand, instructors can conduct organized symposiums and use discussion teaching in class. The four steps of "question-self-study-discussion-solution" can be used to fully mobilize students' subjective initiative and consult literature to understand the latest medical research information and stimulate students' interest in scientific research. Furthermore, collective discussion can stimulate students' creativity and create a strong atmosphere for scientific research [10].

4. Incentive mechanism to arouse students' enthusiasm Faced with the question of whether the largescale venture project can be used as a scholarship evaluation programme, the two groups of students had their own ideas. After coming into contact with literature reading and scientific research practice, many students realize that these practices will increase their study workload, which hinders the application of large-scale innovation projects. As teachers, we should not only inform students of the importance of participating in scientific research and how to arrange their time reasonably but also consider how to improve the enthusiasm of students to participate in scientific research and suggest that scientific research training should be included in the evaluation system. This measure can also increase students' attention to scientific research training. Moreover, spiritual and material affirmation can be awarded to teams, such as credit recognition, bonus points for research and protection, scholarship evaluation, etc. [11].

5. Broaden the experimental platform and integrate the experimental resources Many students hope to increase the laboratory opening time and hope that teachers or graduate students will be on duty for assistance and support. More than $30 \%$ of the students in the two groups want the laboratory to be open all day, and many students want to be able to make an appointment. The former believe that they have heavy workloads and want to use their evening time to conduct experiments, but keeping the laboratory open at all times may cause hidden dangers to the laboratory. The needs of the latter require us to explore a more reasonable laboratory opening system. In view of this situation, we interviewed the person in charge of the experimental project and obtained a preliminary understanding of the system of laboratory opening, including the training and assessment before entering the laboratory; the open reservation platform of the laboratory, including daily equipment reservation information, opening hours and persons in charge of the day (including teachers and graduate students); and the workload and reward system for teachers and graduate students in charge of the laboratory. The ultimate goal is to create conditions for the smooth development of large-scale innovation projects [12].

6. Management of scientific research funds Although the innovation projects of undergraduates are relatively basic, how to optimize the allocation of funds is worthy of in-depth research. Strengthening the management of business expenses, controlling labour expenses and expert consultation expenses, 
properly supervising normal business expenses such as academic conference expenses and study travel expenses, and standardizing the transfer of scientific research funds are important factors. Additionally, student allowances must be clearly listed in the funding plan. Furthermore, the performance evaluation mechanism of scientific research projects should be improved, and a performance evaluation system of scientific research funds should be established.

\section{Conclusions}

In short, how to improve the scientific research and innovation ability of medical students is the focus of higher education research, and the cultivation of innovative talent is by no means an easy task, let alone a project that can be completed by training several students. However, through such research, educators can accumulate relevant experience and create a medical education model that is conducive to cultivating medical students' innovative ability. This process will play an important role in promoting the reform of medical personnel training.

\section{Abbreviations}

Dacheng:College students' entrepreneurship training program

\section{Declarations}

1.Ethics approval and consent to participate The study received approval notice of IRB of the First Affiliated Hospital Of Bengbu Medical CollegeखBYYFY-2019KY05囚and and all participants provided online informed consent.

\section{Consent for publication Not applicable}

3.Availability of data and materials The questionnaire and datasets used and/or analyzed during the current study are available from the corresponding authors upon reasonable request.

4.Competing interests The authors declare that they have no competing interests

5.Funding Analysis of the Present Situation of the Cultivation of Scientific Research and Innovation Ability of Medical Students and Exploration of the Scientific Research Training

\section{Authors' contributions}

YP: Study conceptualisation and design, data analysis, manuscript drafting and revision.

WDC and LL:Study conceptualisation and design

BCC and ZC :Data collection and data entry

HJY and ZJM :Data analysis 
All authors have read and approved the manuscript

I can confirm the personal contribution of the author in the manuscript

7.Acknowledgements We would like to express gratitude to all the participants for participating in this survey.

All authors have read and approved the manuscript

\section{References}

[1] Zhang Xiaoyu, Yang Chao, Luo Yemi, etal. A brief discussion on the cultivation of innovative and practical ability of undergraduates [J]. Education and Teaching Forum, $2019 \varangle 412$ (18): 70-73.

[2]Zou Weiyan, Yan Haiqin, Sun Meiqun, etal. The "Great Innovation Project" is an effective carrier for "excellent doctors" to cultivate innovative ability in the stage of basic medicine-- the experience of guiding the "excellent doctors" project [J]. Journal of Mudanjiang Medical College, 2019 ,40 (5): 166 -168.

[3]Xu Shangfu, Jinfeng, Shi Fuguo, etal. A preliminary study on cultivating the scientific research innovation ability of medical students based on the innovation project of medical undergraduates [J]. Continuing Medical Education in China, 2018 Journal v.10 (04): 35-37.

[4]Qin Chao, Shen Luping, Chenggong, Li Pu, Huang Huaxing. Practice and experience of innovative training for medical students [J]. Journal of Nanjing Medical University: social Sciences Edition, 2016 (3): 249-250.

[5]Huang Huaming, Hu Linhui, che Hongyan. A study on the multiple allocation of postgraduate mentors in higher education [J]. Adult Education in China, 2018,449 (16): 55-57.

[6]Li Jie, Yang Liu, Zou Jiang, etal. Practice and experience of early scientific research training for eightyear medical students [J]. Theory and practice of Medicine, 2017Pol 30 (16): 2487- 2489.

[7]Luo Deng, Zhang Feng, Wang Chen. The enlightening significance of Scientific Research rotation training to Medical students' academic thinking-- taking Shanghai Jiaotong University as an example [J]. Chinese Medical Ethics, 2017,30 (10): 1305-1307.

[8]Yang Chunmei. PBL: an effective mechanism for the integration of graduate course learning and scientific research training [J]. Degree and Postgraduate Education, 2014 (07): 32-37.

[9]Zhang Ting, Zhang Jing. Cultivation of scientific research interest and ability of undergraduates majoring in biology in medical colleges and universities [J]. Journal of Ezhou University, 2014,27 (8): 9698. 
[10]Yu Chihui, Department of Education, Department of Medical Sciences, Peking University, Beijing. Investigation and analysis of the influence of innovative experimental research work of medical undergraduates on medical students' research ability [J]. Higher Medical Education in China, 2014 (7): 2728.

[11]Liu Shuang, Yang Jie, Wu Jie, etal. Investigation on scientific research experience and cognitive status of eight-year clinical medicine students in Peking Union Medical College [J]. Basic Medicine and Clinic, 2018,038 (010): 1505-1508.

\section{Tables}

Due to technical limitations, all tables are only available for download from the Supplementary Files section.

\section{Figures}

Figure 1 View of the time spent on summer training

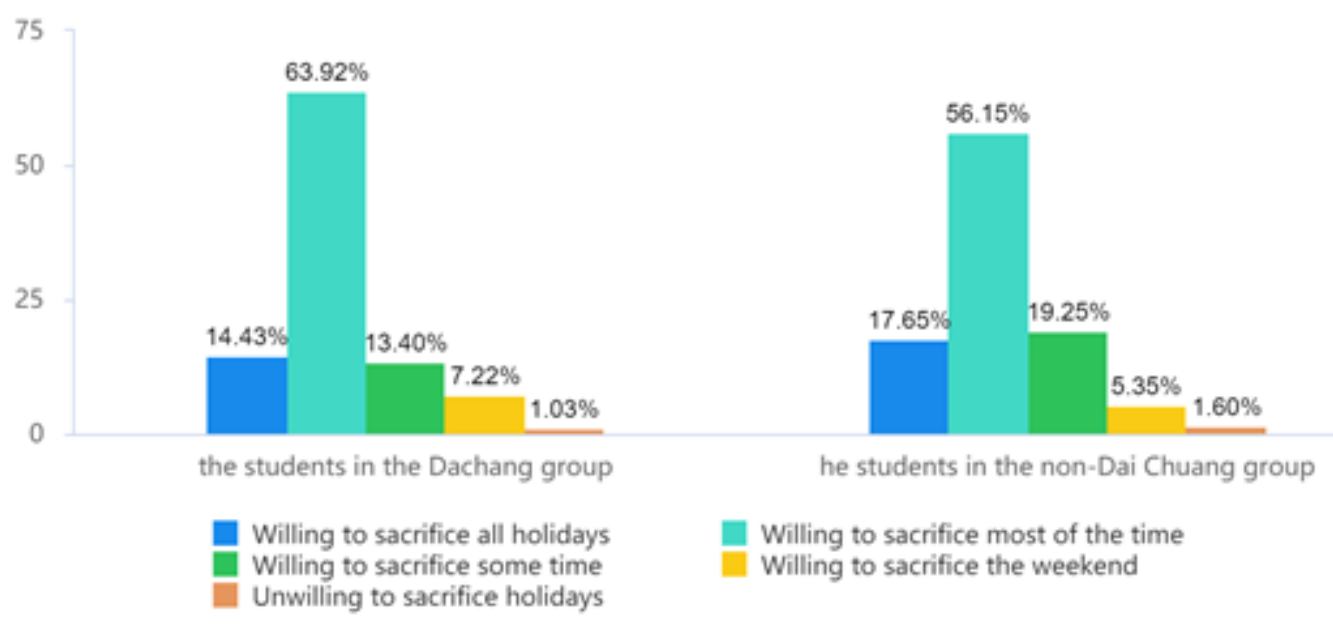

\section{Figure 1}

View of the time spent on summer training 
Figure 2 How do you hope schools promote Dachang development?

the students in the Dachang group

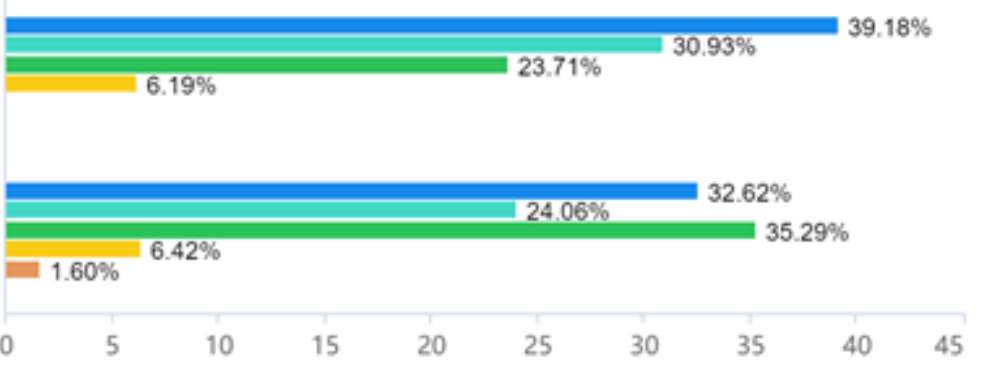

Increase laboratory openness

More teacher participation

Optimize the application process to support an increase in scientific research lectures for undergraduates

More experimental design competitions

Other

\section{Figure 2}

How do you hope schools promote Dachange development?

Figure 3 Students in the Dachang group think that they should be rewarded for their participation

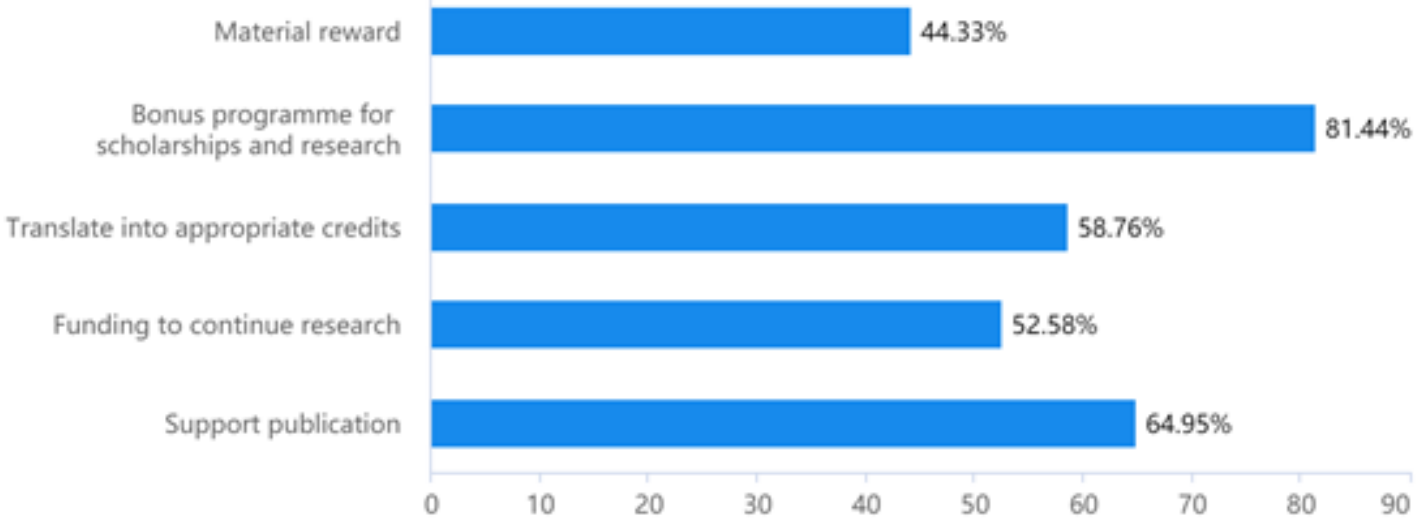

\section{Figure 3}

Students in the Dachang group think that they should be rewarded for their participation 
Figure 4 Rewards that the students in the non-Dachang Group think should be provided for participating in the Dachang

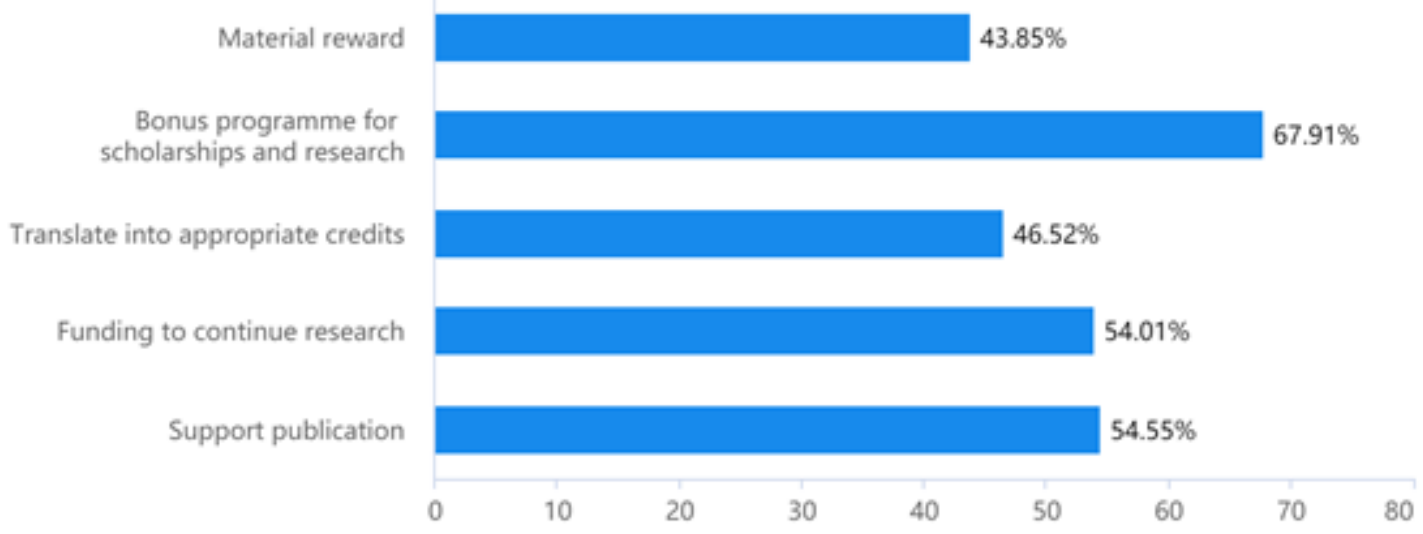

\section{Figure 4}

Rewards that the students in the non-Dachang Group think should be provided for participating in the Dachang

Figure 5 Views of the two groups on opening the laboratories to students

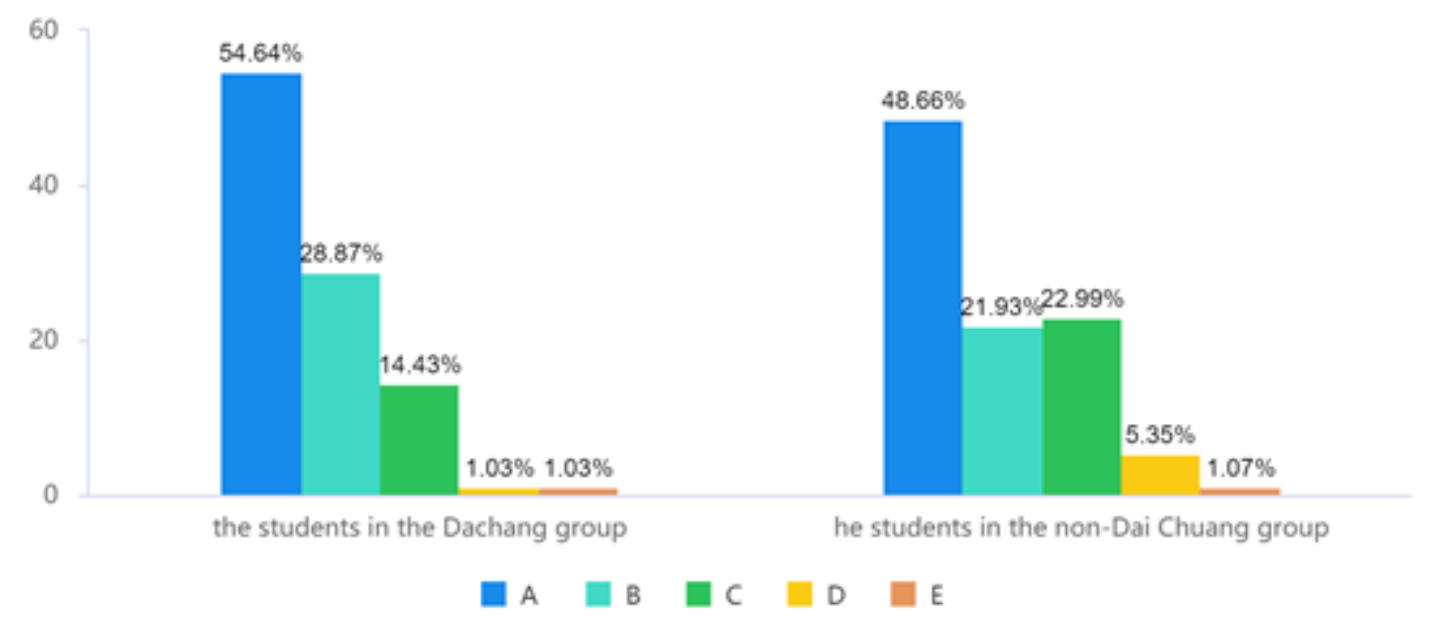

\section{Figure 5}

Views of the two groups on opening the laboratories to students 
Figure 6 Views of laboratory opening hours of the two groups of students

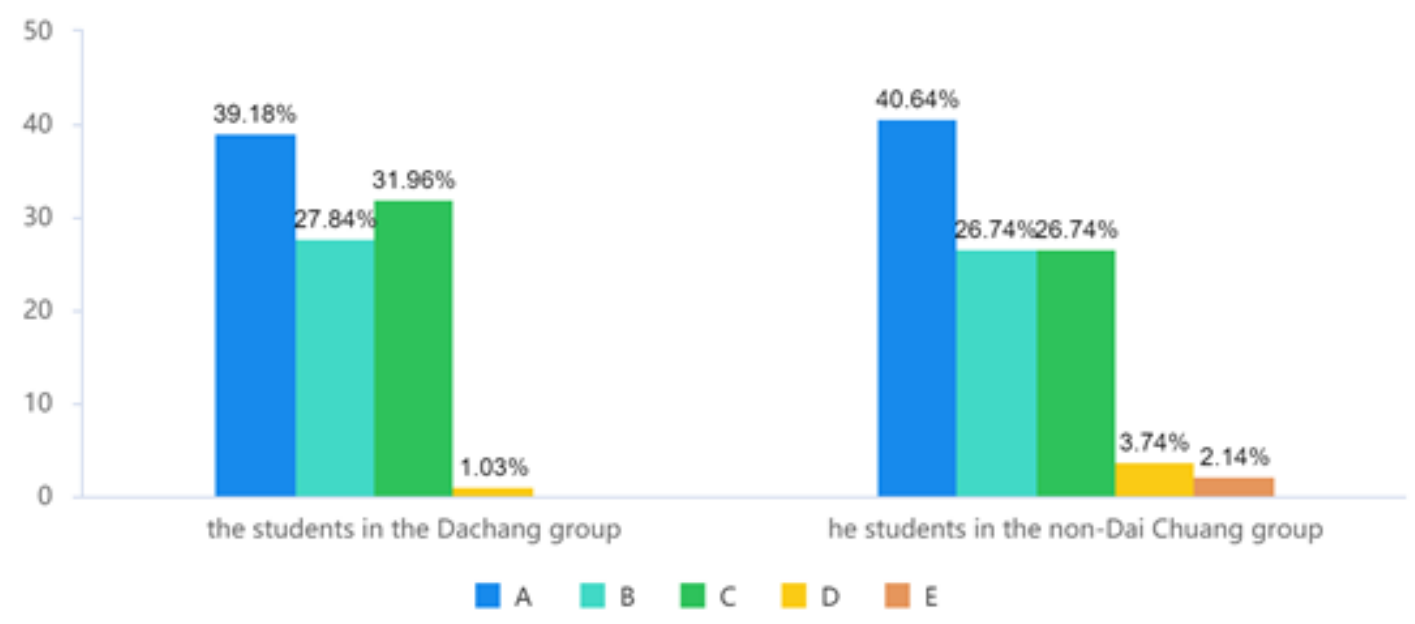

Figure 6

View of laboratory opening hours of the two groups of students

Figure 7 Views on teachers or graduate students teachers being on duty for effective supervision and management

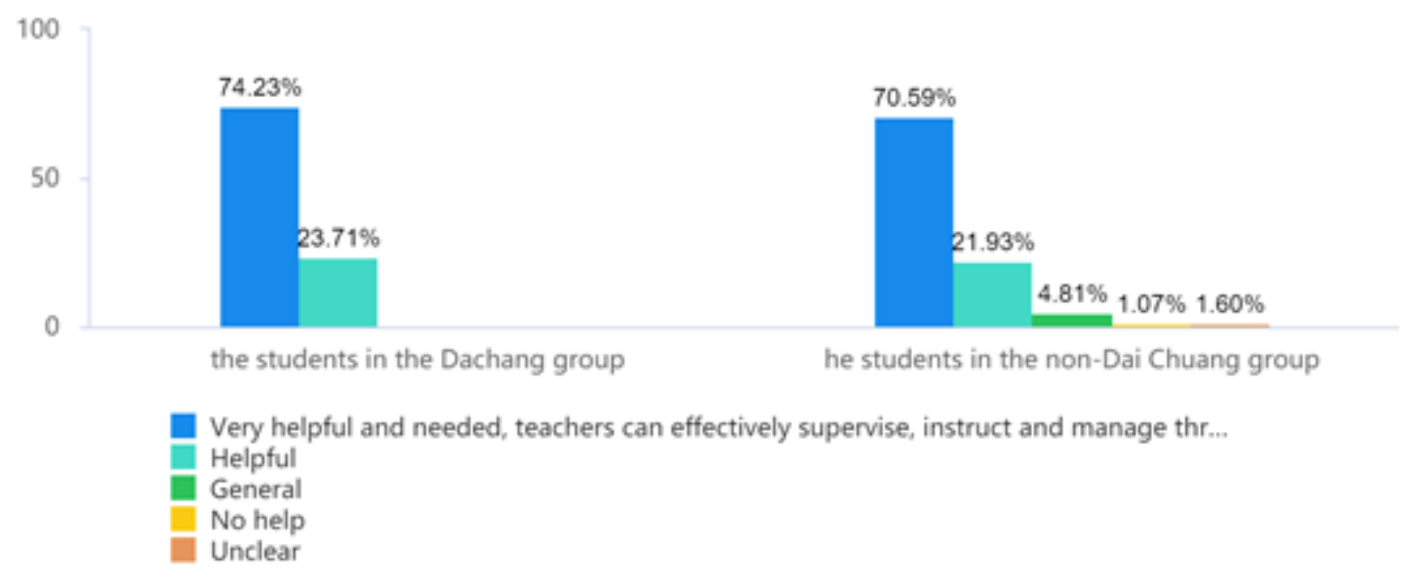

\section{Figure 7}

Views on teachers or graduate students teachers being on duty for effective supervision and management 
Figure 8 Thoughts of the two groups of students on the school' $\mathrm{s}$ allocation of funds

the students in the Dachang group

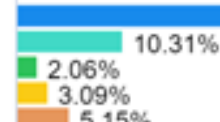

$79.38 \%$

he students in the non-Dai

Chuang group

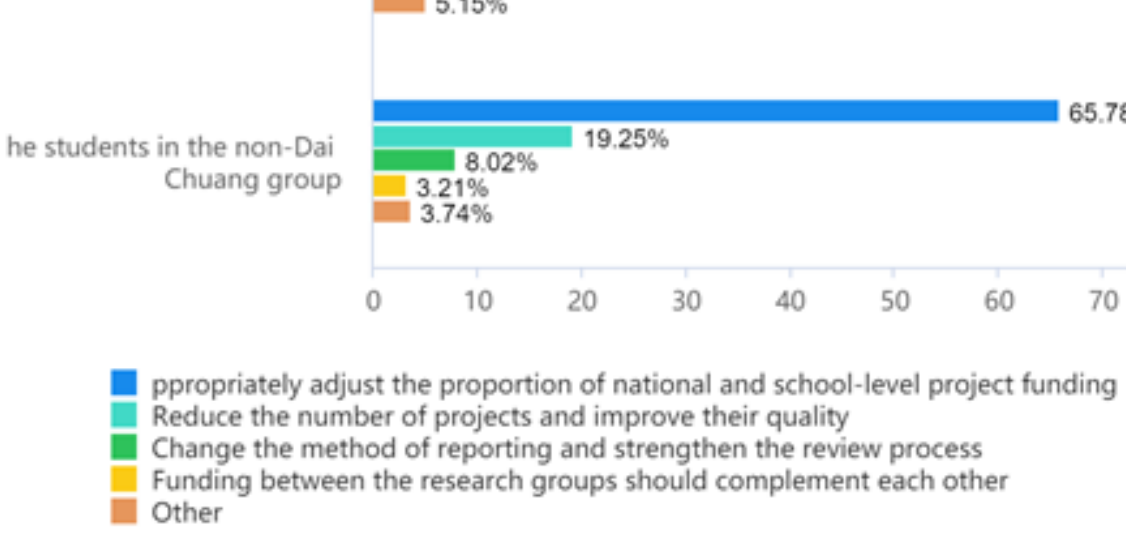

$5.15 \%$

\section{Figure 8}

Thoughts of the two groups of students on the school's allocation of funds

\section{Supplementary Files}

This is a list of supplementary files associated with this preprint. Click to download.

- tables.pdf 